\title{
Work-in-Progress: An Online Journal Tool with Feedback for a Learning Assistant Program in Engineering
}

\section{Dr. Milo Koretsky, Oregon State University}

Milo Koretsky is a Professor of Chemical Engineering at Oregon State University. He received his B.S. and M.S. degrees from UC San Diego and his Ph.D. from UC Berkeley, all in Chemical Engineering. He currently has research activity in areas related engineering education and is interested in integrating technology into effective educational practices and in promoting the use of higher-level cognitive skills in engineering problem solving. His research interests particularly focus on what prevents students from being able to integrate and extend the knowledge developed in specific courses in the core curriculum to the more complex, authentic problems and projects they face as professionals. Dr. Koretsky is one of the founding members of the Center for Lifelong STEM Education Research at OSU. 


\section{Work-in-Progress: An Online Journal Tool with Feedback for a Learning Assistant Program in Engineering}

\section{Overview}

This work-in-progress paper presents the development and pilot implementation of a computerbased reflection tool used in a Learning Assistant (LA) Program in engineering at a large public state university. LAs are undergraduate students who return to a course that they have already completed to help instructors deliver research-based instructional practices. The LA Program at Oregon State University began in 2014 in one department as an effort to provide support for the implementation of active learning in large enrollment Biology courses. Since its start, the program has spread to include courses in five out of seven departments in the College of Science and four out of six departments in the College of Engineering. We identified logistical barriers specific to engineering curriculum and adapted the LA Program developed in the College of Science. We describe here a tool developed to facilitate reflection and instructor feedback of those reflections in one of the engineering units that use LAs.

\section{The LA Program}

The LA Program utilizes the three core elements suggested by the Learning Assistant Alliance (https://www.learningassistantalliance.org/). First, in the LA Pedagogy Seminar, LAs receive pedagogical development in in a formal class with their peers, generally in their first term as an LA. Second, LAs meet weekly with the instructor and the graduate teaching assistants as a member of the instructional team to prepare for active learning in class that week. While LAs elsewhere are often used in large lecture sections, in the context of the unit studied, the LAs facilitated learning in smaller studio or laboratory sessions (Koretsky, 2015; Koretsky et al., ). Third, LAs facilitate active learning in the class in which they are assigned.

Utilization of the LAs to promote student center learning, participating according the three elements of the LA Program, originated in physics (Otero, Pollock, and Finkelstein, 2010). Such use has propagated extensively in the sciences (Jackson \& Koenig, 2017) where there is research evidence that the LA Programs effectively enhance the success of the students in courses that use LAs and of the LAs themselves (Close, Conn, and Close, 2016; Talbot et al. 2015). While the term undergraduate "Learning Assistant" has been reported in ASEE papers for several decades (e.g., Deess et al., 2003; Jaeger et al., 2010), in the past few years the use of "Learning Assistants" in engineering has come to align with the specific three elements proposed by the Learning Assistant Alliance (Cao et al., 2018; Gallegos al., 2018; Tanu et al. 2017; Wendell at al., 2019).

\section{LA Pedagogy Seminar}

An outline of the weekly content of the LA Pedagogy Seminar is shown in Table 1. To prepare for class, the LAs are assigned reading and must respond to a specific prompt that connects to the weekly reading and asks them to reflect on their learning and practice in writing. This process is intended to help them connect the three program elements and build a broader understanding of their own learning and pedagogical practice. It also provides the instructor of the pedagogy 
seminar specific ideas and real experiences to draw upon for class discussion. However, coordinating submission and feedback of the reflections has been challenging.

Table 1. Content, reading, and prompts of the LA Pedagogy Seminar

\begin{tabular}{|c|c|c|}
\hline Week & Topic (Reading) & Prompt \\
\hline 0 & $\begin{array}{l}\text { What Does it mean } \\
\text { to be an LA? }\end{array}$ & \\
\hline 1 & $\begin{array}{l}\text { Role of LA PD } \\
\text { (Goertzen, Scherr, } \\
\text { Elby., 2010) }\end{array}$ & $\begin{array}{l}\text { In this week's reading, Goertzen, Scherr, \& Elby, argue that responsive TA (or } \\
\text { LA) professional development should center upon the beliefs you bring to this } \\
\text { work. Think about teaching and learning in the environment that you are working } \\
\text { in as an LA (e.g. studio, lab, ...). Identify two or three strong beliefs that you have } \\
\text { about your role to support learning in that environment. }\end{array}$ \\
\hline 2 & Status (Horn, 2012) & $\begin{array}{l}\text { In this week's reading, Horn describes the role of status in small group } \\
\text { collaborative learning. Think to your experience as an LA or a student during } \\
\text { small group work. Describe one case where status unproductively influenced a } \\
\text { small group interaction. Describe the interaction, how you interpret the role of } \\
\text { status, and what you think a more positive interaction might have looked like. }\end{array}$ \\
\hline 3 & $\begin{array}{l}\text { Culture of } \\
\text { classrooms; } \\
\text { inclusion (Secules, } \\
\text { Gupta, \& Elby, } \\
\text { 2016) }\end{array}$ & $\begin{array}{l}\text { In this week's reading, Secules, Elby and Gupta discuss the ways in which the } \\
\text { cultural construction of ability in engineering education can exclude some } \\
\text { students whose strengths and skills are not aligned with cultural expectations. } \\
\text { Think about what is important to you as a learner, and about your specific } \\
\text { strengths and skills. Discuss the ways in which your strengths align and do not } \\
\text { align with the cultural construction of ability prevalent in engineering education. }\end{array}$ \\
\hline 4 & $\begin{array}{l}\text { Personal } \\
\text { Epistemology } \\
\text { (Lising \& Elby. } \\
(2005)\end{array}$ & $\begin{array}{l}\text { In this week's reading, the authors describe how one student's assumptions about } \\
\text { knowledge (i.e. her epistemology) affected her experience and learning in a } \\
\text { physics course. Think about a time in a class where you felt uncertain about your } \\
\text { understanding. Describe the ways you tried to increase your certainty, and discuss } \\
\text { what sources of information (e.g. friends, books, your own thoughts) or processes } \\
\text { (e.g. working on homework, googling, going for a walk) helped or hindered the } \\
\text { development of your certainty. }\end{array}$ \\
\hline 5 & $\begin{array}{l}\text { Learning Theories } \\
\text { (Brown, Collins, \& } \\
\text { Duguid, 1989) }\end{array}$ & $\begin{array}{l}\text { In this week's reading, the authors state that in "school culture" what learned is } \\
\text { often abstract and separated from how it is used in the real world. They argue that } \\
\text { such separation is detrimental to developing knowledge that is usable in practice. } \\
\text { Do you agree or disagree that this applies to learning in CBEE? Support your } \\
\text { position with an example from your own experience. The example can be from } \\
\text { school or from when you needed to learn something outside of school. }\end{array}$ \\
\hline 6 & $\begin{array}{l}\text { Conceptual } \\
\text { Understanding }\end{array}$ & Midterm break: no reading or reflection \\
\hline 7 & $\begin{array}{l}\text { Resources and } \\
\text { misconceptions } \\
\text { (Campbell, Schwarz, } \\
\text { \& Windschitl, 2016) }\end{array}$ & $\begin{array}{l}\text { In the Week } 7 \text { reading the authors state, "It's helpful for us as teachers to think } \\
\text { less about correcting misconceptions and more about helping students engage in } \\
\text { science reasoning to try out, evaluate, and refine their resources (ideas, ways of } \\
\text { thinking about the world) to explain real-world phenomena or solve problems." } \\
\text { Do you think this applies to the engineering science courses in CBEE? Provide an } \\
\text { argument to support your position. }\end{array}$ \\
\hline 8 & $\begin{array}{l}\text { Responsive } \\
\text { teaching / questions } \\
\text { (Blosser, 2000) }\end{array}$ & $\begin{array}{l}\text { Describe a conceptually challenging episode that has come up in studio (this can } \\
\text { be either in your role as an LA or as a student). Create a question that you could } \\
\text { ask in this situation for each of the following categories: } \\
\text { Closed question - cognitive memory operation } \\
\text { Closed question - convergent thinking operation } \\
\text { Open question - divergent thinking operation } \\
\text { Open question - evaluative thinking operation }\end{array}$ \\
\hline 9 & THANKSGIVING & \\
\hline
\end{tabular}




\begin{tabular}{|l|l|l|}
\hline 10 & $\begin{array}{l}\text { Metacoginition, } \\
\text { reflection \& winter } \\
\text { / spring (Tanner, } \\
2012)\end{array}$ & $\begin{array}{l}\text { Over the term, many of you have had opportunity to interact with students in class } \\
\text { and we have all had a chance to discuss and reflect on this aspect in the pedagogy } \\
\text { class. Think about teaching and learning in the environment that you are working } \\
\text { in as an LA or as a student (e.g. studio, lab, ...). Identify two or three strong } \\
\text { beliefs that you have about your role to support learning in that environment. }\end{array}$ \\
\hline
\end{tabular}

\section{The LA Reflection Tool}

The reflection tool was piloted and developed iteratively over two years in the LA pedagogy seminar in engineering at Oregon State University. It contains a student interface where students are directed to respond to a weekly prompt and an instructor interface to select prompts and to provide feedback. The LA reflection tool is available for faculty to use in their courses through the Concept Warehouse (Koretsky et al., 2014; cw.edudiv.org).

A partial screenshot of the student interface is provided in Figure 1, which shows a student responding to the week 3 prompt (see Table 1). A more extensive screenshot of the same student view which shows the student's access to previous reflections and previous instructor comments in the submission interface is shown in Appendix A. The tool allows the instructors to choose a weekly prompt or to select from a list of commonly uses prompts; a screenshot of the instructor assignment page is shown in Appendix B. It also allows for quick anonymous feedback of the student reflections, as shown on the screenshot in Appendix C. The tool has a set of common prompts for an instructor to use, but also gives instructors the ability to create their own prompts.

\section{Research in Progress}

The reflection tool can be used for instruction since it provides the instructor access to students' perspectives on how they make sense of their role of being an LA and the challenges they face. For example, it provides formative information where the instructor can read student thinking in advance of class to enable thoughtful ways to facilitate class activity and discussion. It also allows summative information; for example, it allowed the pedagogy instructor to recognize that two of the weekly readings were too advanced for the students; these readings will be changed next year.

The reflection tool is also a data source for education research around LA sense-making of their role in teaching and the changes in their thinking associated with the LAs first term experience. In that vein, we are currently performing a research study using the LAs reflection data as follows. Weekly reflections were collected from twenty-four LAs during the pedagogy course from the same department. All participant provided informed consent to be in the study. 


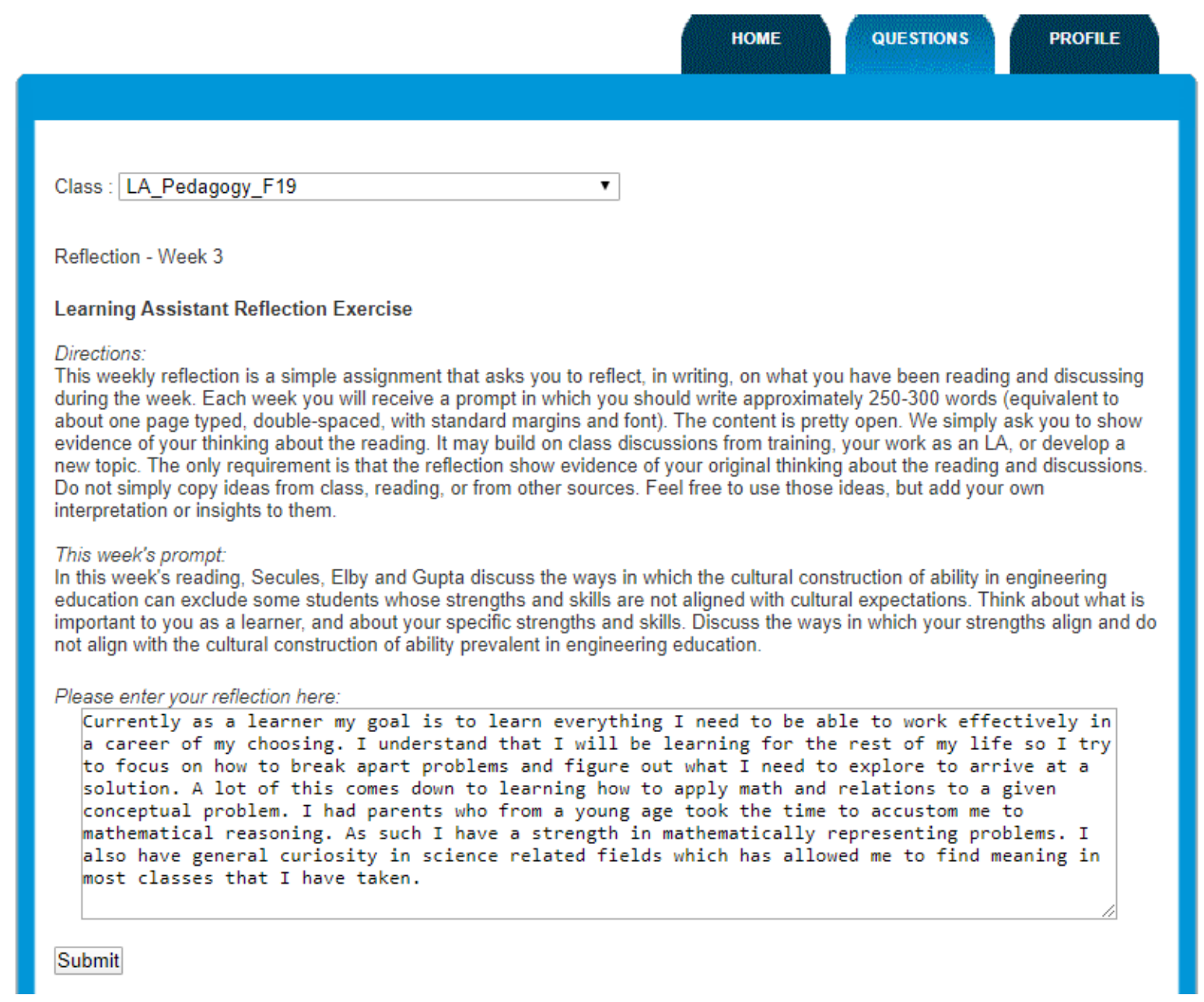

Figure 1. Screenshot of part of the student view of the LA Reflection Tool for Week 3. See Appendix A for a more complete view.

As shown in Table 1, in both weeks 1 and 10, LAs responded to the prompt, "Think about teaching and learning in the environment that you are working in as an LA (e.g. studio, lab, ...). Identify two or three strong beliefs that you have about your role to support learning in that environment." Thematic coding is being used to characterize the aspects that the LAs identify as salient to teaching, the ways their thinking has shifted, and what concepts from the LA pedagogy seminar are being incorporated into their thinking. We ask the following research questions:

1. What are the common elements of the beliefs that LAs bring to instruction? How do LAs differ in their expressions around these beliefs?

2. How have the expressed beliefs shifted over the first term of the LA experience? What concepts from the LA pedagogy course are incorporated into the second reflection?

Students bring different histories-in-person to their instructional role. The first research question allows a composite description of the perspectives and priorities from this cohort of LAs. This fine-grained description of the values and beliefs that LAs bring to their work can help inform future professional development strategies. Importantly, these beliefs are drawn from the same 
schooling environment and culture that TAs and faculty also participate in. We intend to pursue the ways that differences in beliefs connect to the activity system (ref) of doing school, and in that way generate knowledge that might be more broadly transferred to those interested in organizational change around research-based instructional practices.

The second question allows us to explore the ways that the LAs conceptions of their instructional practice has shifted. As we iteratively develop our code categories we notice core ideas from the pedagogy seminar translated into the expressed beliefs of the LAs. For example, several responses in week 10 focused on status, which was discussed in week 2 , but reinforced throughout the term. As one LA wrote, "n studios, another strong belief I have is that students shouldn't be afraid to ask questions. Sometimes, ideas around status, popularity, or competence prevent students from asking questions. This fear limits the opportunity for students to use studios as an environment to learn and grow." We also see general shifts in beliefs, e.g., from a more "transmission-based" conception of learning to a more constructivist view.

\section{References}

Blosser, P. (2000). How to Ask the Right Questions. National Science Teachers Association. Brown, J. S., Collins, A., \& Duguid, P. (1989). Situated cognition and the culture of learning. Educational researcher, 18(1), 32-42.

Campbell, T., Schwarz, C., \& Windschitl, M. (2016). What we call misconceptions may be necessary stepping-stones toward making sense of the world. Science and Children, 53(7), 28

Cao, Y., \& Smith, C., \& Lutz, B. D., \& Koretsky, M. (2018, June), Cultivating the Next Generation: Outcomes from a Learning Assistant Program in Engineering Paper presented at 2018 ASEE Annual Conference \& Exposition, Salt Lake City, Utah. https://peer.asee.org/30244

Close, E. W., Conn, J., \& Close, H. G. (2016). Becoming physics people: Development of integrated physics identity through the Learning Assistant experience. Physical Review Physics Education Research, 12(1), 010109.

Deess, E. P., \& Gonzalez-Lenahan, C., \& Briller, V., \& Calluori, R., \& Carpinelli, J. (2003, June), The Educational Learning Assistants Program: Increasing Retention Of The Engineering And Computer Science Sophomores Paper presented at 2003 Annual Conference, Nashville, Tennessee. https://peer.asee.org/12428

Gallegos, H., \& Wendell, K. B., \& Swenson, J. E. S. (2018, June), WIP An Interview Study of Faculty, Course Assistant, and Student Insight within Teaching and Learning Assistant Programs for Undergraduate Engineering Courses Paper presented at 2018 ASEE Annual Conference \& Exposition, Salt Lake City, Utah. https://peer.asee.org/31244

Goertzen, R. M., Scherr, R. E., \& Elby, A. (2010). Respecting tutorial instructors' beliefs and experiences: A case study of a physics teaching assistant. Physical Review Special TopicsPhysics Education Research, 6(2), 020125.

Horn, I. S. (2012). Strength in Numbers. Reston, VA: National Council of Teachers. (Chapter 3)

Jackson, H. E., \& Koenig, K. (2017, June), Board \# 62 : Enhancing Engineering Student Learning in Foundational STEM Courses of Biology, Chemistry, Mathematics, and Physics: Transforming the Faculty Culture Paper presented at 2017 ASEE Annual Conference \& Exposition, Columbus, Ohio. https://peer.asee.org/27892 
Jaeger, B., \& Balint, C., \& Wishon, C., \& Fritze, C. (2010, June), Atlas Academic Teaching And Learning Assistants Study: The Use Of Peers As 'Quality Managers' In Engineering Class Instruction Paper presented at 2010 Annual Conference \& Exposition, Louisville, Kentucky. https://peer.asee.org/16446

Koretsky, M. D. (2015). Program level curriculum reform at scale: Using studios to flip the classroom.

Koretsky, M. D., Falconer, J. L., Brooks, B. J., Gilbuena, D. M., Silverstein, D. L., Smith, C., \& Miletic, M. (2014). The AIChE" Concept Warehouse": A Web-Based Tool to Promote Concept-Based Instruction. Advances in Engineering Education, 4(1), n1.

Koretsky, M., Montfort, D., Nolen, S. B., Bothwell, M., Davis, S., \& Sweeney, J. (2018). Towards a stronger covalent bond: pedagogical change for inclusivity and equity. Chemical Engineering Education, 52(2), 117-127

Lising, L., \& Elby, A. (2005). The impact of epistemology on learning: A case study from introductory physics. American Journal of Physics, 73(4), 372-382.

Otero, V., Pollock, S., \& Finkelstein, N. (2010). A physics department's role in preparing physics teachers: The Colorado learning assistant model. American Journal of Physics, $78(11), 1218-1224$.

Secules, S., \& Elby, A., \& Gupta, A. (2016, June), "Turning away" from the Struggling Individual Student: An Account of the Cultural Construction of Engineering Ability in an Undergraduate Programming Class Paper presented at 2016 ASEE Annual Conference \& Exposition, New Orleans, Louisiana. 10.18260/p.26239

Talbot, R. M., Hartley, L. M., Marzetta, K., \& Wee, B. S. (2015). Transforming undergraduate science education with learning assistants: student satisfaction in large-enrollment courses. Journal of College Science Teaching, 44(5), 24-30.

Tanner, K. D. (2012). Promoting student metacognition. CBE-Life Sciences Education, 11(2), 113-120.

Tanu, E. D., \& Quan, G. M., \& Gupta, A., \& Turpen, C. A. (2017, June), The Role of Empathy in Supporting Teaching Moves of Engineering Design Peer Educators Paper presented at 2017 ASEE Annual Conference \& Exposition, Columbus, Ohio. https://peer.asee.org/29004

Wendell, K. B., \& Matson, D., \& Gallegos, H., \& Chiesa, L. (2019, June), Board 53: Work in Progress: Learning Assistant "Noticing” in Undergraduate Engineering Science Courses Paper presented at 2019 ASEE Annual Conference \& Exposition, Tampa, Florida. https://peer.asee.org/32372 


\section{Appendix A: Screenshot of student view during week 3 reflection}

Class

$$
\text { LA_Pedagogy_F19 }
$$

Reflection - Week 3

Learning Assistant Reflection Exercise

Directions:

This weekly reflection is a simple assignment that asks you to reflect, in writing, on what you have been reading and discussing during the week. Each week you will receive a prompt in which you should write approximately 250-300 words (equivalent to about one page typed, double-spaced, with standard margins and font). The content is pretty open. We simply ask you to show evidence of your thinking about the reading. It may build on class discussions from training, your work as an LA, or develop a new topic. The only requirement is that the reflection show evidence of your original thinking about the reading and discussions Do not simply copy ideas from class, reading, or from other sources. Feel free to use those ideas, but add your own interpretation or insights to them.

This week's prompt:

In this week's reading, Secules, Elby and Gupta discuss the ways in which the cultural construction of ability in engineering education can exclude some students whose strengths and skills are not aligned with cultural expectations. Think about what is important to you as a learner, and about your specific strengths and skills. Discuss the ways in which your strengths align and do not align with the cultural construction of ability prevalent in engineering education.

Please enter your reflection here:

Currently as a learner my goal is to learn everything I need to be able to work effectively in a career of my choosing. I understand that I will be learning for the rest of my life so I try to focus on how to break apart problems and figure out what I need to explore to arrive at a solution. A lot of this comes down to learning how to apply math and relations to a given conceptual problem. I had parents who from a young age took the time to accustom me to mathematical reasoning. As such I have a strength in mathematically representing problems. I also have general curiosity in science related fields which has allowed me to find meaning in most classes that I have taken.

Submit

See table below for your responses to previous reflection exercises in this class:

Prompt: In this week's reading, Horn describes the role of status in small group collaborative learning. Think to your experience as an LA or a student during small group work. Describe one case where status unproductively influenced
Your Reflection (2019-10-09 14:16:52): There was a time when I was a student when the table I was sitting at was split into two groups to complete the assignment that we had been given. By random chance, the two other people I was sitting with were also high achievers. Our half of the table consistently finished the different sections before the other half and as a result when it came time for discussion on the section it was assumed that our group was right and the discussion became more of a answer check for the other half. I think that this hampered not only the other groups ability to think critically about the problems but also our ability to understand the material on a deeper level.

I believe that the status gained from being able to deal with the problems in a timely manner allowed for my group to dominate the interaction without realizing it. In this case status indicated to both of our teams that our answer was correct even if the reasons behind the correct answers were fuzzy. To improve this interaction what should of happened was after both groups had solved it we should have worked through the problem step by step. This would allow the other group to think about the

\section{(continued on the next page)}


See table below for your responses to previous reflection exercises in this class:

\begin{tabular}{|c|c|}
\hline \multirow[t]{2}{*}{$\begin{array}{l}\text { Prompt: In this week's } \\
\text { reading, Horn describes } \\
\text { the role of status in small } \\
\text { group collaborative } \\
\text { learning. Think to your } \\
\text { experience as an LA or a } \\
\text { student during small } \\
\text { group work. Describe one } \\
\text { case where status } \\
\text { unproductively influenced } \\
\text { a small group interaction. } \\
\text { Describe the interaction, } \\
\text { how you interpret the role } \\
\text { of status, and what you } \\
\text { think a more positive } \\
\text { interaction might have } \\
\text { looked like. }\end{array}$} & $\begin{array}{l}\text { Your Reflection (2019-10-09 14:16:52): There was a time when I was a student when } \\
\text { the table I was sitting at was split into two groups to complete the assignment that we } \\
\text { had been given. By random chance, the two other people I was sitting with were also } \\
\text { high achievers. Our half of the table consistently finished the different sections before } \\
\text { the other half and as a result when it came time for discussion on the section it was } \\
\text { assumed that our group was right and the discussion became more of a answer check } \\
\text { for the other half. I think that this hampered not only the other groups ability to think } \\
\text { critically about the problems but also our ability to understand the material on a deeper } \\
\text { level. } \\
\text { I believe that the status gained from being able to deal with the problems in a timely } \\
\text { manner allowed for my group to dominate the interaction without realizing it. In this } \\
\text { case status indicated to both of our teams that our answer was correct even if the } \\
\text { reasons behind the correct answers were fuzzy. To improve this interaction what } \\
\text { should of happened was after both groups had solved it we should have worked } \\
\text { through the problem step by step. This would allow the other group to think about the } \\
\text { problem more while cementing my groups understanding of the problem in greater } \\
\text { detail as we have to explain our thinking. By jumping straight to the answer } \\
\text { comparison and skipping the discussion learning opportunities were lost. An open } \\
\text { dialog on the problem with discussion on the underlying reasons for the steps we took } \\
\text { would have added greater comprehension. }\end{array}$ \\
\hline & $\begin{array}{l}\text { Instructor Feedback: This scenario is related to a topic brought up in class on Friday, } \\
\text { the idea that "faster is smarter." This is something that contributes to status often, and } \\
\text { blame shouldn't be put on the students who are fast. Our education system teaches us } \\
\text { to be fast and rewards us for it. I like the ideas and solutions you are presenting to } \\
\text { make the experience better for everyone. How can you use these ideas, and your high } \\
\text { status as an LA, to enhance group learning in the studio environment? Thanks for your } \\
\text { response! }\end{array}$ \\
\hline \multirow[t]{2}{*}{$\begin{array}{l}\text { Prompt: In this week's } \\
\text { reading, Goertzen, } \\
\text { Scherr, \& Elby, argue that } \\
\text { responsive TA (or LA) } \\
\text { professional development } \\
\text { should center upon the } \\
\text { beliefs you bring to this } \\
\text { work. Think about } \\
\text { teaching and learning in } \\
\text { the environment that you } \\
\text { are working in as an LA } \\
\text { (e.g. studio, lab, ...). } \\
\text { Identify two or three } \\
\text { strong beliefs that you } \\
\text { have about your role to } \\
\text { support learning in that } \\
\text { environment. }\end{array}$} & $\begin{array}{l}\text { Your Reflection (2019-10-01 20:41:39): My teaching environments: Studio \& Office } \\
\text { hours } \\
\text { I believe that the two different areas in which I will be assisting students should have } \\
\text { different approaches. For studi I think that my job is to access what students are } \\
\text { thinking about the problem and guide it in a productive direction while letting them do } \\
\text { most of the reasoning. I think the most productive way to do this is to ask a question } \\
\text { that gets at the underlying topic that they are thinking about and having the group } \\
\text { generate ideas. It is possible that sometimes I will need to be devils advocate but I } \\
\text { never try to defeat students in an argument but try to get them to think about it from } \\
\text { different perspectives. I also think that is important to tell them when something is your } \\
\text { opinion. For example if I were to set up a problem a certain way that I think lends itself } \\
\text { towards an easier solution I would acknowledge that other people might want to set it } \\
\text { up a different way. } \\
\text { I think that this differs from office hours because the students have had more time to } \\
\text { think over the problem before coming to me. I would tend to agree more with Alan from } \\
\text { the reading in this area. The students have had the time to think and struggle over the } \\
\text { problem when they come to office hours and thus are probably at the end of their } \\
\text { patience with the problem they are thinking on; if I were to answer their questions } \\
\text { indirectly the may become so frustrated that they no longer trust me to assist them } \\
\text { when they need it. Since office hours are on a more individual level, I believe that } \\
\text { having them do the problem in front of you and correcting math mistakes or logic } \\
\text { errors by asking them leading questions is a more productive and trust building use of } \\
\text { time. }\end{array}$ \\
\hline & $\begin{array}{l}\text { Instructor Feedback: Thank you for communicating your thoughts! I find it interesting } \\
\text { that you're looking at this prompt through two different lenses. I agree that promoting } \\
\text { group work and deep thought is helpful in studio, but it may not be as applicable in } \\
\text { office hours. It can still be valuable to ask a student to explain their thoughts and work } \\
\text { so far, as this can better inform you about their understanding. Some students might } \\
\text { be completely lost, while others might only need a light nudge in order to resolve their } \\
\text { misunderstanding. Thanks again for your time! }\end{array}$ \\
\hline
\end{tabular}




\section{Appendix B: Screenshot of Instructor assignment interface}

Label (visible to students):

Reflection - Week 3

田

Add short answer followup.

$\square$ Add confidence followup.

$\square$ Add group followup.

Assign - Manual Stop

Assign - Homework Start: 2019-10-11 08:00:00

Due: 2019-10-17 17:00:00

Timezone: (GMT-08:00) Pacific Standard Time (US \& Canada) $\quad \checkmark$

Cancel

IMPORTANT: Before clicking one of "Assign" buttons above, be sure to select a prompt below.

[Status in small group] -- In this week's reading, Horn describes the role of...

Full text of selected prompt:

In this week's reading, Horn describes the role of status in small group collaborative learning. Think to your experience as an LA or a student during small group work. Describe one case where status unproductively influenced a small group interaction. Describe the interaction, how you interpret the role of status, and what you think a more positive interaction might have looked like.

\section{NOTES}

1. The prompt labels shown in brackets will not be visible in the Student Interface.

2. Please choose prompt carefully. You will not be able to change it later.

Create New Prompt

Prompt label (30 char max):

Prompt text: 


\section{Appendix C. Screenshot of Part of the Anonymous Instructor Feedback Interface}

\begin{tabular}{|c|c|c|c|}
\hline Date & Prompt & Please enter your reflection here: & Instructor feedback \\
\hline 23:07:29 & $\begin{array}{l}\text { In this week's reading, Secules, } \\
\text { Elby and Gupta discuss the ways } \\
\text { in which the cultural construction } \\
\text { of ability in engineering } \\
\text { education can exclude some } \\
\text { students whose strengths and } \\
\text { skills are not aligned with } \\
\text { cultural expectations. Think } \\
\text { about what is important to you as } \\
\text { a learner, and about your specific } \\
\text { strengths and skills. Discuss the } \\
\text { ways in which your strengths } \\
\text { align and do not align with the } \\
\text { cultural construction of ability } \\
\text { prevalent in engineering } \\
\text { education. }\end{array}$ & $\begin{array}{l}\text { As a learner, I need to be passionate about what is it I'm learning. If I'm not interested in the material, I will not } \\
\text { spend as much time and effort into truly understanding core concepts. Learning new things and being able to } \\
\text { apply it to real world problems gives me a sense of accomplishment, which in turn boosts my confidence } \\
\text { regarding my own abilities. As this continues, I feel more prepared to take on challenges and really explore } \\
\text { what the world has to offer. } \\
\text { It usually takes a while for me to really understand and apply new material. I must study and practice for hours } \\
\text { until I feel confident solving unique problems with this new information. I, however am extremely driven and } \\
\text { persistent in my studies. I may not be the fastest at understanding how to apply new ideas, but I will continue to } \\
\text { practice problems until I'm able to comfortably deduce final answers on examinations. } \\
\text { The passion I have for BioEngineering is a great indicator as to how hard I will work to be successful in the } \\
\text { field. This strength aligns with the cultural construction of ability that is so prevalent in engineering education. } \\
\text { One of my weaknesses is not fully grasping new concepts or engineering notions that are needed to solve } \\
\text { complex problems. When subject matter doesn't fully register, being able to apply it at studio or recitations is } \\
\text { almost near impossible. This frustrates me as I haven't been able to fully interpret information. As a result, I } \\
\text { take much longer to complete these assignments, and am often perceived as someone with less of an idea as to } \\
\text { what's going on in class. }\end{array}$ & \begin{tabular}{|l} 
Thank you for sharing your thoughts! You're \\
fortunate to align with the cultural \\
construction of ability in this field. Keep in \\
mind that some people do not align with this \\
construction in one way or several ways. \\
\end{tabular} \\
\hline 2019-10-15 & $\begin{array}{l}\text { In this week's reading, Secules, } \\
\text { Elby and Gupta discuss the ways } \\
\text { in which the cultural construction } \\
\text { of ability in engineering } \\
\text { education can exclude some } \\
\text { students whose strengths and } \\
\text { skills are not aligned with } \\
\text { cultural expectations. Think } \\
\text { about what is important to you as } \\
\text { a learner, and about your specific } \\
\text { strengths and skills. Discuss the } \\
\text { ways in which your strengths } \\
\text { align and do not align with the } \\
\text { cultural construction of ability } \\
\text { prevalent in engineering } \\
\text { education. }\end{array}$ & $\begin{array}{l}\text { My strengths are primarily align with speed and work ethic, which are highly valued in engineering education. I } \\
\text { am able to work fast on exams and I am often in the first few to finish, however that is all preceded by hours of } \\
\text { practice on homework and additional problems. Work ethic is essential in learning engineering, and it heavily } \\
\text { denotes a level of ability. However, ability can be defined in many ways, and engineering has a cultural } \\
\text { construction that often prizes speed and test scores. It is likely that many students do not thrive under the } \\
\text { pressure of exams, however this doesn't mean they are "not fit" for engineering. Other important factors, such } \\
\text { as asking questions and working in groups, are prevalent in engineering education. One strength I do not have is } \\
\text { asking questions or participating in discussions at a great speed. I am much better at putting my thoughts on } \\
\text { paper than speaking out loud, so by the time my thoughts are organized a different topic is being discussed. I } \\
\text { view this as a strength to be able to take in material and digest it deeply before stating my thoughts, however in } \\
\text { engineering education it often does not feel like a strength because there is a cultural construction of speed in } \\
\text { discussions and lectures. Cultural construction in engineering education affects status and a student's perception } \\
\text { of ability, which is highly beneficial for some but the opposite of how other students may prefer to learn. }\end{array}$ & $\begin{array}{l}\text { I agree that speed and work ethic are highly } \\
\text { valued in our education system. Whenever you } \\
\text { feel like you are disadvantaged due to the } \\
\text { cultural construction (e.g. in fast-paced } \\
\text { discussions), remember that different poople are } \\
\text { advantaged or disadvantaged in a wide variety or } \\
\text { areas. Thanks for your response! } \\
\end{array}$ \\
\hline $\begin{array}{l}\text { 2019-10-15 } \\
14: 49: 47\end{array}$ & $\begin{array}{l}\text { In this week's reading, Secules, } \\
\text { Elby and Gupta discuss the ways } \\
\text { in which the cultural construction } \\
\text { of ability in engineering } \\
\text { education can exclude some } \\
\text { students whose strengths and } \\
\text { skills are not aligned with } \\
\text { cultural expectations. Think } \\
\text { about what is important to you as } \\
\text { a learner, and about your specific }\end{array}$ & $\begin{array}{l}\text { As a learner, I believe having an understanding of the fundamentals and taking notice of "hints" given by } \\
\text { problems either in class or in real life to find solutions, is what can be most important to make learning relatable } \\
\text { to real life application. My strengths are generally focused on my ability to simplify explanation of difficult or } \\
\text { technical subjects down to analogy or simpler language that more people can find easier to understand. Another } \\
\text { strength I do have is breaking down quantitative problems down to easy to memorize solution base points that } \\
\text { are more less kept in my "toolbox" of knowledge, so that if a similar type of problem arrives, I can immediately } \\
\text { pull it out to solve things. However, in engineering education one's strength is generally measured by how fast } \\
\text { can someone come up with a correct solution, no matter what thought process they went through, along with } \\
\text { only just focusing on what is correct or not, not whether you can explain why. For me, solving and explaining } \\
\text { problems takes more time just so I can understand concepts and explain it well to help others. I generally live by }\end{array}$ & $\begin{array}{l}\text { I agree that speed is highly valued in our education } \\
\text { system. This leaves many people disadvantaged though } \\
\text { it may not be extremely relevant to what we are being } \\
\text { trained for. There are many other ways that people } \\
\text { can be advantaged or disadvantaged by our constructed } \\
\text { culture, keep that in mind as an LA! } \\
\end{array}$ \\
\hline
\end{tabular}

